\title{
7 \\ The role of games in a model company
}

\author{
Jens O. Riis 1), Uffe Thorsteinsson ${ }^{2)}$, Ari Barfod ${ }^{3)}$, Erik \\ Lyngsie ${ }^{4)}$
}

1) Department of Production, Aalborg University, Fibigerstraede 16, DK-9220 Aalborg, Denmark. E-mail: riis@iprod.auc.dk

2) Department of Production Engineering and Industrial Management, Building 423, Technical University of Denmark, DK-2800 Lyngby, Denmark.E-mail: uffet@ipv.dtu.dk 3) Department of Applied Engineering Design and Production Management, Building 358, Technical University of Denmark, DK-2800 Lyngby, Denmark

4) Section for Industrial Engineering and Management, Copenhagen Engineering College, Lautrupvang 15, DK2750 Ballerup, Denmark

\begin{abstract}
Professional engineers should be capable of developing innovative and holistic solutions. This constitutes an important challenge to the future engineering education. In a joint project between engineering schools in Denmark a Model Company is being developed to be available on the internet.

Various pedagogical means will be employed in connection with using the Model Company. In particular the paper will focus on the potential role of games for stimulating creative, holistic thinking. To illustrate we shall present a proposed game for creative development of a production concept and outline ideas for two games to demonstrate the virtues and limitations of next generation manufacturing.

This will point to new areas of applying games with the prospect of preparing engineering students for the challenges of the professional engineer.

Keywords

Simulation games, creativity, holistic thinking, next generation manufacturing
\end{abstract}




\section{CHALLENGES TO TEACHING PRODUCTION MANAGEMENT}

Teachers of production management are confronted with many challenges in their effort to continuously develop and adopt new teaching approaches and methods to prepare engineering graduates for a professional career. Not only are most universities under sustained pressure to reduce costs and at the same time increase effectiveness. But new market conditions for industrial enterprises request a closer integration of the various disciplines of production, such as production planning \& control, production processes, plant-layout, organizational structure and behavior. Furthermore, the production tasks should be seen in a broader context as related to marketing, product development as well as vendors and suppliers in the supply chain. Emerging production paradigms and principles call for a thorough discussion of potential benefits and limitations.

Some of the fundamental challenges are:

- How to give students a comprehensive appreciation of the dynamic nature of production planning \& control

- How to train students for the unstructured and non-linear analyses they will have to carry out in their professional career

- How to give students proficiency in practical design of new systems and methods

- How to train students in both re-engineering and innovation.

Over the years many different means of teaching production management have been developed, such as in-class exercises, case studies, simulation and games of various kinds. An overview of simulation games for production management is given in Riis (1995).

In this paper we shall particularly address the third and fourth challenges mentioned in the list above.

There is a general appreciation of project work in the engineering education as a means for developing skills in unstructured problem-solving, integration of different disciplines and teamwork. A grand American program on Engineering Education Coalitions involves a large number of engineering schools in various networks in an effort to develop and implement means for training students in a practical problem-oriented synthesis with the use of teamworking modes, e.g. Coleman (1996). The program was initiated in 1990 and includes several engineering disciplines.

In Europe an increasing number of engineering schools has included project work in their curriculum, as for instance witnessed by the number of visitors to the Aalborg University which has practiced the project work mode extensively since its start in 1974, cf. Kjærsdam (1994). Most of such student projects take an industrial issue as point of departure; some are carried out at the universities and initiated by a written introduction to the issues more or less building on the tradition of case stories; others involve an industrial enterprise. The latter type has clear advantages 
by exposing the students to an ill-structured situation in which they themselves are to gather information and analyze the company to relate performance to the actual operations. This calls for a broad integrative approach to analysis and diagnosis which has often been neglected in traditional teaching. Furthermore, project work in an existing industrial enterprise gives students an opportunity not only to develop new holistic solutions, but also to address the important issue of implementation.

However, the project mode also has limitations. It is time and resource consuming, and the issues, for good reasons, are dominated by the current mode of operations, and seldomly lend themselves to the development of solutions for future production conditions. One of the challenges that we have identified thus has been to develop a pedagogical setting which would capture most of the features of the project working mode, and at the same time be more economical in operations, yet allowing for coping with next generation production systems.

In this paper we shall first present our effort to build a model company and its vision for being able to address a variety of pedagogical situations. Then, three proposed new games will be outlined and discussed with respect to the challenges introduced above. As they are in a preliminary design stage, ideas and alternative directions are welcomed.

\section{A MODEL COMPANY}

In a joint development project between several engineering schools in Denmark a Model Company is being developed. It will be based on a new product which has been developed, called SnapHane, an equipment for private households to almost automatically brew beer of high quality and with a large variety of different tastes. The product has mechanical and electrical parts and must be able to control chemical processes. A cooling component is essential for securing high quality.

The beer brewing machine is imagined placed in the basement or in the kitchen and has a capacity of 20 liter. The brew may either be served directly as draught beer or bottled. The company will offer kits with all necessary ingredients for brewing a large variety of different tastes.

The students enter the model company in its fifth year of operation and have access to information about the start of the company, its sales for each year, drawings specifying the product, the necessary production processes for the parts manufactured in the company, manufacturing facilities, plant-layout, methods of production planning and control, marketing effort, economical situation, organizational structure, etc.

The data base of the company and its operation in the first five years will be available on Internet allowing for an interconnected presentation of information using hypertext capabilities. To support the students a large model bank is being established with different types of models for analysis and design. 
A basic version of the Model Company will be developed in 1997, and a network of European universities is being established with the prospect of broadening the scope of the Model Company and secure its further development.

\section{1 Pedagogical situations to be addressed}

The Model Company may be used in many different ways. The primary focus is on integration in industrial enterprises, and the main pedagogical idea is to offer opportunities for students to work with unstructured and complex issues and to experience a more student-driven learning process for non-linear analysis and synthesis. The Model Company should be used as an integral part of other pedagogical means, such as lectures, group discussions, exercises, project work, etc.

We would like to use the Model Company to practice three phases of problem solving, namely

- The Analysis and Diagnosis Phase, in which an understanding of the nature of the issues and problems is sought. It concludes with a structure of proposed focal areas for improvements.

- The Solution Development Phase, in which first a conceptual solution and later a detailed solution are developed. A solution ordinarily includes different aspects, such as production processes, plant-layout, management systems and organizational aspects.

- The Implementation Phase, in which the organization is being prepared for changes, acceptance of the solution sought, and the solutions implemented.

In the basic version we plan to develop a number of exercises aimed at the analysis and diagnosis phase. They will be initiated by the description of a specific incident as a motivation for students to start analyzing the Model Company. For example,

- The sales department has received several requests from dealers to be allowed to offer a discount on model B of 15 per cent. This has initiated the following question from the managing director: "Where do we actually make our profit?"

- Recent difficulties with meeting the promised delivery dates has spurred the production manager to wonder if new bottlenecks have appeared in the flow of customer orders and materials: "Where are the bottlenecks, and what may explain our failure to deliver on time?"

- The managing director has for some time noticed a widespread dissatisfaction in the company, and he senses that conflicts of interest constitute a major cause. Is this true?

The model company will provide a pedagogical setting in which a student is experiencing a non-linear process of analyzing a complex situation in which the student must determine which data would be helpful.

Each of the situations described above may, after the Analysis and Diagnosis Phase, automatically lead to the Solution Development Phase by asking the 
students to propose solutions which may cure the identified problems. This will develop skills to re-engineer the Model Company. Such pedagogical activities also will lend themselves to consider the time horizon of various solutions, because inevitably the students would have to discuss whether a proposed solution could be implemented right away, or would presuppose other parts of the company to be changed first. Traditional exercises encourage the development of just one solution which would meet the specified goals. To the contrary, project work in an industrial company will stimulate the students to realize that any acceptable solution always has a time horizon associated as a suffix. In this way several acceptable solutions exist, each of which indicates within which time horizon the solution may be realized.

We believe that working with the Model Company will encourage students to consider a spectrum of acceptable solutions and to also discuss the implementation phase.

In addition to work with re-engineering in the Solution Development Phase, we find the Model Company suitable for dealing with more creative problem solving and for discussing more dramatically different types of solutions. To illustrate the capability of the Model Company to also address futuristic issues we shall outline three games in the next section.

\section{SKETCH OF THREE NEW GAMES}

It is our experience from working for more than two decades with project work in industrial companies that the students most often perceive the problems that they have uncovered and structured in their analysis and diagnosis as a re-engineering issue. Consequently, they propose a solution which may be implemented within the near future. This is partly due to the interest expressed by the company. Too seldom would the students be challenged to develop a more far sighted solution including a vision of the future company.

We see the Model Company as an opportunity to let students work with more futuristic solutions to prepare them for a professional career in which they have proficiencies in creative systems design.

\section{1 Creative development of a new production concept}

The initial situation in this game is the fifth year of the Model Company. The students are told that a year ago the company was taken over by a major brewery with a strong financial capability. The new owner envisages that the current annual sales of 16.000 units within three years with a concerted effort could be increased to 80.000 units. However, this would require that the sales price be cut into one half, yet with increased functionality and quality of the product. Thus, there is a need for creative thinking in terms of developing a new concept for production, marketing and product design. 
The situation presented should convince the teams that they must indulge in a creative development process. The current solutions represent a point of departure, but cannot be used for meeting the new challenges.

After an initial analysis and diagnosis each team will be encouraged to identify requirements for the new production system. It may be followed by a "dreaming stage" in which ideas and suggestions of elements of a new production system are developed. Eventually an integrated concept or vision will emerge to be used for a first, coarse evaluation and, if accepted, for developing a detailed configuration of subsystems (production technology, management systems, organization, etc.).

In industrial enterprises and in our lab we are experimenting with the process of developing an integrated, innovative concept or vision, and we plan to continue this effort. We hope to be able to point to means for stimulating this process and would like to also use games as a pedagogical means.

In the game the teams will be asked to develop rather specific plans and expected results for the following year.

To put this exercise described so far into a game context, we propose that each team presents their proposed concept, detailed solution and the expected results to the board of the Model Company. It will consist of experienced manager from industry as well as some of the teachers. The board will question and critique the presentation, and afterwards the game management will use a model to decide the results of the following year (Year 6). This is communicated to the teams and used in their future work, e.g. adjusting the concept, long-term plans and the plans and expected results for the following year (Year 7).

The plans and expected results are presented to the board again followed by a discussion and feedback. The board does not know the decision model, so they are even with the teams. The game management will communicate what will actually happen in year 7.

In this way the teams will learn the effect of their concept and more detailed planning through discussions and feedback from a group of experienced industrialists. We believe that this way of creating a game situation is both realistic and feasible.

Based on our experience from previous games, we see no need for imposing a direct competition among teams. On the other hand, it would be good to stimulate the teams to exchange experience, thus creating a positive learning situation guided by a natural interest in how the other teams are doing.

As mentioned above, the pedagogical mechanism in the game is (1) to let the teams develop expected results of their proposed concept and plans, and (2) to let an experienced group of industrialists give constructive feedback.

\section{2 Next generation production systems}

The literature on new emerging paradigms for manufacturing are most often presented as ideals in which the positive properties and characteristics are delineated and no mentioning is made of any limitations. In a class room setting the teacher is left with the possibility to present the claimed virtues and to make an attempt to 
differentiate the new paradigm from previous ones. The students would be likely to accept the beauty of the new paradigm and remember the few most important key characteristics for later use as Buzz Words in their engineering career.

If student project work is used in industry, it is our experience that students and their advisors may have difficulty with persuading the company to make experiments with a new paradigm, let alone that the effort and time needed normally exceeds the scope of the student project.

Thus, there is a need at a professional engineering school to offer students an effective and efficient way of learning the advantages and limitations of new emerging production paradigms.

In the following we shall present ideas for using a game in connection with the Model Company to demonstrate two new paradigms, Lean Thinking and The Selfdriven Organization.

The idea with the two games is to immerse students into a company which follows the new paradigm. Everything will function according to the ideals of the paradigm. The aim of the game is first to demonstrate how life in an organization is with the new paradigm and secondly to let the students find the limits of functionality. In this way the students may acquire a more comprehensive understanding of the new paradigm than the frequently seen binary assessment in which you are either for the new paradigm or you are against it.

\section{3 Lean Thinking}

In the first game described in section 3.1 the Model Company was in its fifth year of operation and great challenges lied ahead. Now the Model Company has successfully moved to its tenth year of operation, and everything functions according to the principles of Lean Thinking. Particular focus will be placed on one or two supply and distribution chains to demonstrate the behavior of interacting, but legally independent organizational units. Our assumption is that if Lean Thinking can be brought to function successfully in such a situation, then it may be applied broadly.

In contrast to many of the usual games we have used and developed, the first step is not to look for ways of improving the system or organization, but to realize what it takes on part of each member of the organization and the needed interplay to fulfill the intentions of Lean Thinking. To support this goal we imagine that in the game IT would be used to its most feasible extent and that most of the interaction between partners in the chains are guided by rules and procedures built into the management systems.

When first accustomed to the lean mode of operation, the players should be subjected to a number of incidents which would help them realize the underlying assumptions and limitations of Lean Thinking. Examples of incidents are:

- A request from a number of customers to decrease the delivery time to one half within a period of six months

- A significant jump in sales of, say $\mathbf{4 0} \%$ 
- The introduction of a new product in the chain, requiring capability changes in the in the chains

Each group of players in charge of an organizational unit will be asked to analyze their own situation and to react to the imposed changes. But an important part, we imagine, would be to engage participants in negotiations with the other units in the chains.

In this way, the game may help demonstrate and train what it takes to maintain lean thinking in manufacturing. Furthermore, the dimension of learning should also be attended to on the basis of the actual behavior of players in the game.

The game, thus, will provide a setting for demonstrating the necessary prerequisites for a supply and distribution chain to function according to the principles of lean thinking and to realize the limitations of Lean Thinking.

We find that the Model Company will provide an appropriate setting for the game on Lean Thinking outlined. However, not all elements of the company need to be active in this game. We believe that it would be possible to focus attention on just a few links in one or two chains, say altogether five to seven organizational units interacting.

\section{4 The Self-driven Organization}

Another area in next generation manufacturing in which it would be useful to gain a more subtle understanding is what we have named "The Self-driven Organization". In recent years, several research groups have developed ideas around this notion, such as Holonic Manufacturing, The Fractal Company, and Bionic Manufacturing. The underlying idea, or dream, is to establish an organization which consists of a number of interacting units, each of which is capable of adapting intelligently to external changes in such a way that the overall goals of the company are achieved. As discussed in a Danish industrial enterprise, we imagine that a worker keeps an eye on what is going on in his group and perhaps also outside. If something unusual occurs, she will on her own initiative seek to adjust appropriately alone or in her group. The notion of self-driven organization captures this feature that each member of the organization takes initiative to adjustments and improvements.

It is hard to find anybody who would object to this idea. On the other hand, little help is available for seeking answers to questions like: What would it take to realize this idea? What is the area of applicability? What are the limitations?

The game to be proposed in this section purports to give participants experiences on the basis of which they may discuss the three questions raised above. It will require that participants work in a group not as a self-contained entity, but as an integral part of the whole organization.

Several settings may be used. We find that the assembly of the Model Company may provide a useful context for a game. We have not yet decided on the type of activities to take place in the group, but some kind of physical activities would help participants to recognize a need for cooperation within and outside the group. 
It may be assembly and test of simple pieces of paper, wood, plastic, or the like, representing parts and components of the Model Company's products.

A given assignment of roles may get the group started. But changed demand may suggest a more flexible mode of working within the group. The debriefing periods in-between game sessions should be used to analyze and reflect on the activities of the preceding session. This is an opportunity to discuss the notion of individual responsibility to take initiative and the development of collective behavioral patterns in support of a self-driven mode of operation. The session should also be used to plan the next game session.

We imagine that the group should be supported by advanced IT, including capabilities for learning from past experience.

At the end of the game, players should be asked to dream up the ideal working mode for the group, with respect to both the internal handling of the tasks and the external interplay. This would provide insight into the participants' perception of the self-driven organization.

Much attention in the literature on Holonic Manufacturing is given to cybernetic studies of automatic adoption to externally imposed changes. We find that the focus in this game should rather be on the capability of human players to develop selfdriven behavioral patterns. This will require a change of attitude and behavioral skills on part of the participants, but also a capability of the management systems to provide transparency with respect to the role and functioning of the group in the company context.

As has become evident, we are not very far in developing this game. As the concept of the game becomes more specific, existing games should be reviewed for adoption, either fully or partially.

\section{SUMMARY AND CONCLUSION}

In view of the future role of professional engineers, the capability to develop innovative and holistic solutions constitutes an important challenge to the future engineering education. In a joint project between engineering schools in Denmark a Model Company is being developed to meet this challenge.

Various pedagogical means to be employed in connection with using the Model Company were discussed. In particular the paper has focused on the potential role of games of various kind. To illustrate we proposed one game for creative development of a production concept and two games for demonstrating the virtues and limitations of next generation manufacturing.

In many ways this has pointed to new areas of applying games with the prospect of preparing engineering students for the challenges of the professional engineer.

The effort needed for developing the proposed games is large for which reason we would like to invite colleagues to join our endeavor. 


\section{REFERENCES}

Coleman, Robert J. 1996: The Engineering Education Coalition, ASEE PRISM, Sept.

Kjærsdam, Finn and Stig Enemark, 1994: The Aalborg Experiment. Project Innovation in University Education, Aalborg University Press. ISBN 87-7307-4802.

Riis, Jens O. (Editor) 1995: Simulation Games and Learning in Production Management, Chapman \& Hall, UK. 0-412-72100-7.

\section{BIOGRAPHY}

Jens O. Riis is Professor of Industrial Management Systems at the Department of Production, Aalborg University. His research areas include industrial management, technology management and project management.

Uffe Thorsteinsson is Associtate Professor at the Department of Production Engineering and Industrial Management, the Technical University of Denmark. His major areas of interest are plant-layout, project management, and transportation and logistics.

Ari Barfod is Professor at the Department of Applied Engineering Design and Production Management, the Technical University of Denmark. His research areas include systems analysis and design, and production management.

Erik Lyngsie is Associate Professor at the Section for Industrial Engineering and Management, Copenhagen Engineering College. His major area of interest is production planning and control. 